\title{
The Vibration Based Fatigue Damage Assessment of Steel and Steel Fiber Reinforced Concrete (SFRC) Composite Girder
}

\author{
Chen $\mathrm{Xu}^{1, \mathrm{a}}$, Saiji Fukada ${ }^{2}$ and Hiroshi Masuya ${ }^{3}$ \\ ${ }^{1}$ Kanazawa University, Graduate School of Natural Science and Technology, Kanazawa, 920-1192, Japan \\ ${ }^{2}$ Kanazawa University, Graduate School of Natural Science and Technology, Kanazawa, 920-1192, Japan \\ ${ }^{3}$ Kanazawa University, Graduate School of Natural Science and Technology, Kanazawa, 920-1192, Japan
}

\begin{abstract}
The steel-concrete composite girder has been usually applied in the bridge and building structures, mostly consisting of concrete slab, steel girder, and shear connector. The current fatigue damage assessment for the composite girder is largely based on the strain values and concrete crack features, which is time consuming and not stable. Hence the vibration-based fatigue damage assessment has been considered in this study. In detail, a steel-steel fiber reinforced concrete (SFRC) composite girder was tested. The steel fiber reinforced concrete is usually considered for dealing with the concrete cracks in engineering practice. The composite girder was $3.3 \mathrm{~m}$ long and $0.45 \mathrm{~m}$ high. The fatigue load and impact excitation were applied on the specimen sequentially. According to the test results, the concrete crack development and global stiffness degradation during the fatigue test were relatively slow due to the favourable performance of SFRC in tension. But on the other hand, the vibration features varied significantly during the fatigue damage development. Generally, it confirmed the feasibility of executing fatigue damage assessment of composite bridge based on vibration method.
\end{abstract}

\section{Introduction}

The steel-concrete composite girder has usually been applied in the bridge and building structures, consisting of concrete slab, steel girder and shear connector in general. It benefits from the material advantages such as the compressive strength of concrete and tensile strength of steel. However, the deficiency like the tensile concrete cracks because of the weak tensile performance has to be dealt with carefully regarding to the negative flexural region of continuous composite girder. So far, the steel fiber reinforced concrete has been considered one of the ways dealing with concrete cracks in engineering practice [1]. Moreover, compared to the normal concrete bridges, the steel-concrete composite girder bridges with lower self-weight are more easily influenced by the fatigue problems. Since there exists a large amount of potential aging bridges in the next ten years in Japan, The corresponding fatigue damage assessment is increasingly concerned. The current fatigue damage assessment is largely based on concrete strain monitor and concrete cracks observation, which are more or less time consuming and may experience inaccuracy problems. Hence the vibration-based fatigue damage assessment has been considered in this study. Particularly, the natural frequency, corresponding vibration mode, etc were observed through the carried out impact tests during the fatigue damage development. These observations were expected to indicate the fatigue damage induced stiffness degradation and severe damage locations.

\section{Test works}

A steel-steel fiber reinforced concrete (SFRC) composite girder was designed and tested. The fatigue load and impact load were applied on the specimen sequentially for inducing the fatigue damage, deriving the vibration modes and corresponding frequencies.

\subsection{Test specimens}

The specimen layout is shown in Figure1. The composite girder was $3.3 \mathrm{~m}$ long and $0.45 \mathrm{~m}$ high. The steel I girder was $0.35 \mathrm{~m}$ high and the SFRC slab width was nominally $0.6 \mathrm{~m}$. Moreover, the individual length and diameter of the embedded steel fibers with end hooks were $30 \mathrm{~mm}$ and $0.6 \mathrm{~mm}$. Its volume percentage in concrete was $1.0 \%$, and its tensile strength was more than $1080 \mathrm{MPa}$. The studs arranged in groups were applied as shear connectors between the concrete slab and steel girder, which was for simulating the slab prefabrication situation. The stud diameter and length were $13 \mathrm{~mm}$ and $80 \mathrm{~mm}$, respectively. The diameters of the reinforcements and stirrups in the concrete were both $10 \mathrm{~mm}$, and the reinforcement ratio was $1.8 \%$.

\footnotetext{
${ }^{a}$ Corresponding author: xuchenprc@hotmail.com
} 

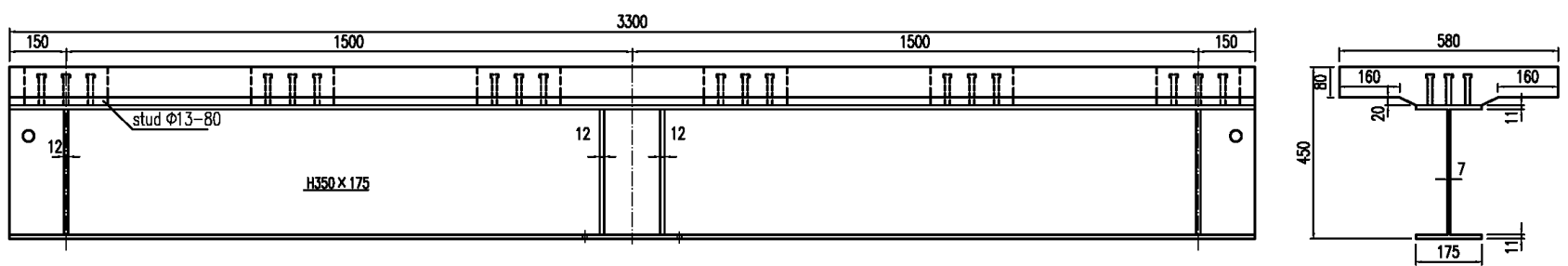

Figure 1. Specimen layout (mm).

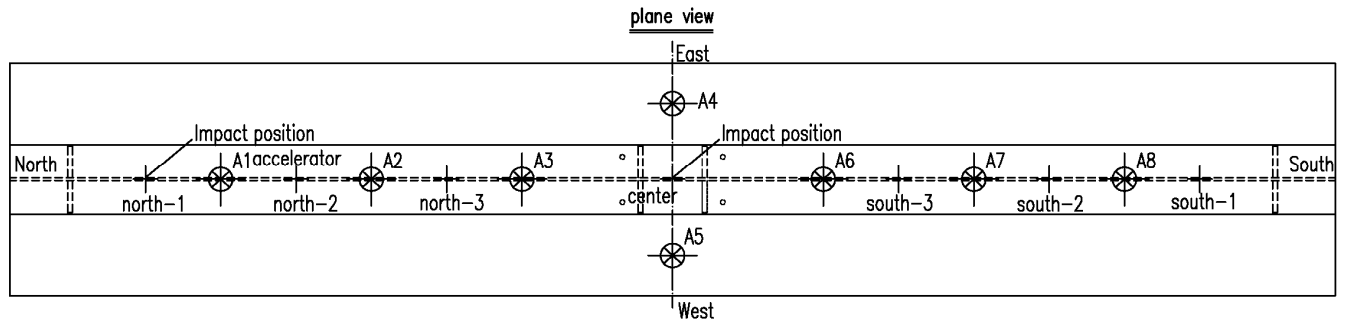

Figure 4. Impact positions and accelerators.

\subsection{Test setup}

The simply supported girder was turned over for deriving the negative flexural moment by the vertical load actions applied at the middle, as shown in Figure 2, which included the static and fatigue loads (Figure 2a) and the impact load (Figure 2b). The detail procedure of these load actions is illustrated in Figure 3. The static and impact tests were carried out several times at certain numbers of fatigue load cycles to investigate the fatigue induced mechanical degradation and to correlate such degradation to the vibration feature variation of the specimen. Moreover, after the 2 million fatigue load cycles, a static failure test was carried out. And the last impact test was executed after the failure test.

Concerning the detail fatigue load procedure, it was a fatigue load with various amplitude constants as listed in Table 1. They sequentially contained $80 \mathrm{kN}, 20 \mathrm{kN}, 10 \mathrm{kN}$, $15 \mathrm{kN}, 20 \mathrm{kN}, 25 \mathrm{kN}$. Moreover, the cyclic load peak were constantly $108 \mathrm{kN}$, corresponding to the value of necessary load for introducing concrete cracks with $0.1 \mathrm{~mm}$ maximum crack width.

As to the impact tests as shown in Figure $2 \mathrm{~b}$, the falling weight was $5 \mathrm{~kg}$, impacting the specimen from the $12 \mathrm{~cm}$ height at the positions as shown in Figure 4, including center, north-1 to 3 and south-1 to 3 .

Table 1. Fatigue load amplitudes.

\begin{tabular}{|r|c|c|c|}
\hline Load cycles & Load valley $(\mathrm{kN})$ & Load peak $(\mathrm{kN})$ & Range $(\mathrm{kN})$ \\
\hline 0 to 1400 & 29 & 108 & 80 \\
\hline 1401 to 2000 & 88 & 108 & 20 \\
\hline 2001 to 0.5 million & 98 & 108 & 10 \\
\hline 0.5million to 1million & 93 & 108 & 15 \\
\hline 1million to 1.5million & 88 & 108 & 20 \\
\hline 1.5million to 2 million & 83 & 108 & 25 \\
\hline
\end{tabular}

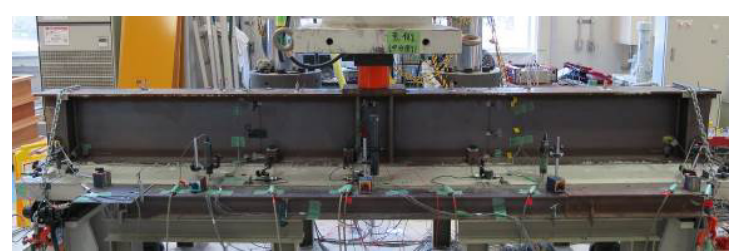

a) Fatigue and static test setup.

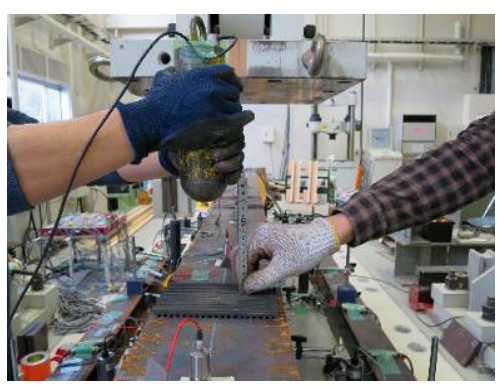

b) Impact test.

Figure 2. The test setup.

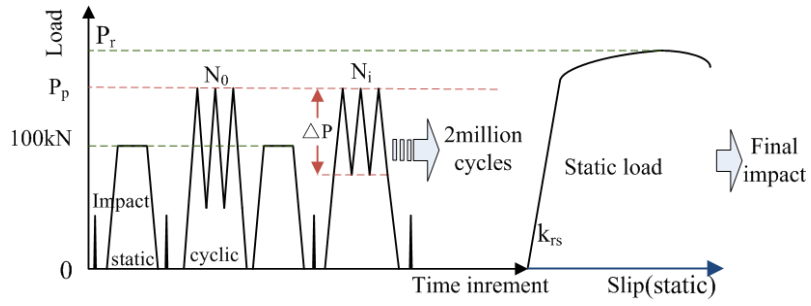

Figure 3. Load procedure in test.

\subsection{Material properties}

The uniaxial compression and splitting tension tests on the concrete were carried out after 7 days and 28 days curing in terms of JIS-A-1108 [2] and JIS-A-1113 [3]. The compression test specimens were cylinders, $200 \mathrm{~mm}$ high with a diameter of $100 \mathrm{~mm}$. The splitting tension test specimens were cylinders as well, $150 \mathrm{~mm}$ high with a diameter of $150 \mathrm{~mm}$. The material modulus was also measured and listed in Table 2. Moreover, the tested 
yield and ultimate stress of stud were 380.4 and 455.5 MPa based on JIS-Z-2241[4], respectively.

Table 2. Material property.

\begin{tabular}{|c|c|c|c|c|c|c|}
\hline \multirow{2}{*}{ Concrete type } & \multicolumn{2}{|c|}{7 days $\left(\mathrm{N} / \mathrm{mm}^{2}\right)$} & \multicolumn{3}{c|}{ 28days(N/mm²) } \\
\cline { 2 - 7 } & $\mathrm{f}_{\mathrm{c}}$ & $\mathrm{f}_{\mathrm{t}}$ & $\mathrm{E}$ & $\mathrm{f}_{\mathrm{c}}$ & $\mathrm{f}_{\mathrm{t}}$ & $\mathrm{E}$ \\
\hline Normal & 29.8 & 2.3 & 8345 & 43.9 & 2.4 & 32708 \\
\hline SFRC & 28.1 & 2.7 & 8188 & 36.4 & 3.4 & 29700 \\
\hline
\end{tabular}

(Note: $f_{c}$ is the compressive strength; $f_{t}$ : tensile strength; $E$ : Young's modulus)

\subsection{Sensors}

Part of the sensor arrangements are shown in Figure 5, which included the slip sensors, the deflection sensors and the accelerators.

In particular, there were 10 displacement sensors set longitudinally along with the girder specimen for monitoring the girder deflection, which located at the positions of the specimen centre, the ends and the places with $0.5 \mathrm{~m}$ apart from the centre. Meanwhile, there were also 10 slip sensors set along with the steel-concrete interlayers for slip monitoring. The positions were the same to those deflection sensors. In addition, strain gauges were mounted on the steel girder, the concrete slab, the embedded reinforcements and several studs in order to observe the sectional strain distribution and the connector's performance.

On the other hand, there were 8 accelerators mounted on the girder flange as well for getting the vibration features such as vibration frequency and modes. They located at the positions of those from the $1 / 8$ span to the $8 / 8$ span. The A4 and A5 accelerators as shown in Figure 5 were mounted on the concrete slab for avoiding the position overlap of the impact and fatigue loads.
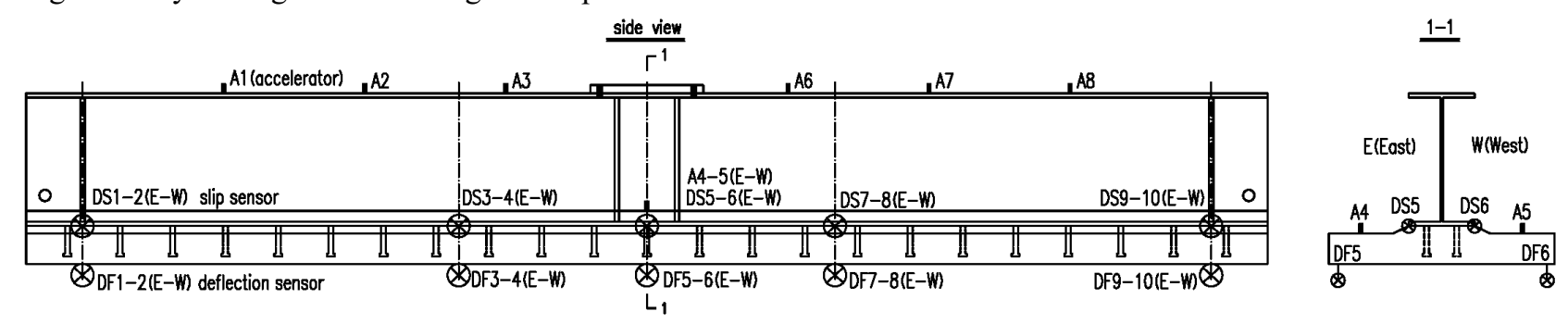

Figure 5. Arrangement of accelerators, slip sensors and deflection sensors.

\section{Test results}

\subsection{Failure mode}

As shown in Figure 6, the test failure mode appeared as the concrete slab tensile failure and the following the yielding and buckling at the steel flange and nearby web area. The maximum concrete crack width was $1.9 \mathrm{~mm}$.

Figure 6a shows the ultimate deflection overview of the specimen. Figure $\mathbf{6 b}$ shows the ultimate crack distribution on the concrete slab surface, contributed by the tensile stress. The cracks with large crack widths mainly concentrated in the middle of the specimen. On the other hand, the cracks passing through the group studs holes were found to be rare. Moreover, Figure $6 \mathbf{c}$ and $\mathbf{6 d}$ presents the buckling of the steel flange and web. The buckling were found after the tensile failure of the concrete slab where the maximum crack width was above $1.2 \mathrm{~mm}$. In fact, the results of the buckled steel flange and web strains showed that these parts had already yielded before buckling.

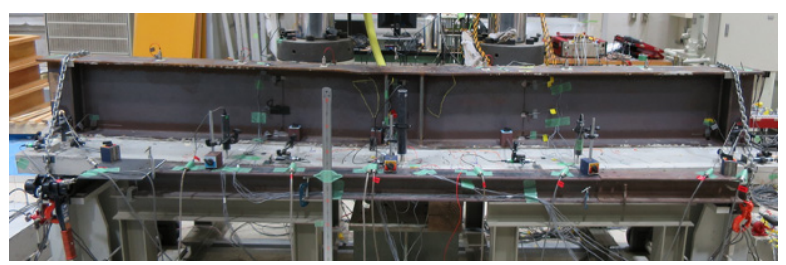

a) The ultimate condition of the test specimen.

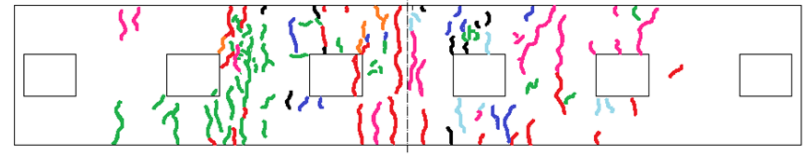

b) The ultimate crack distribution on the concrete slab surface.

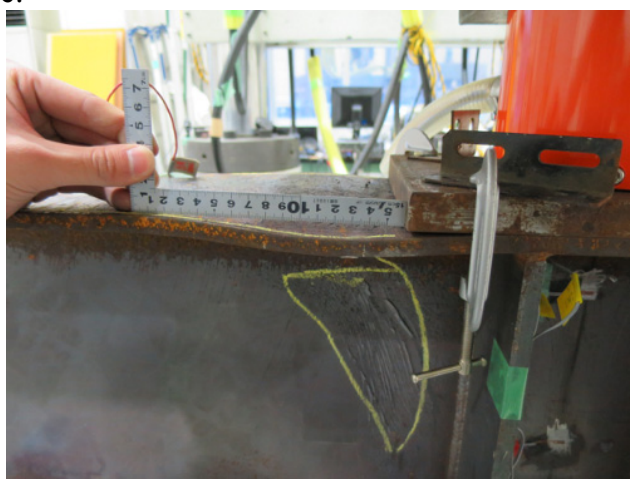

c) The flange buckling.

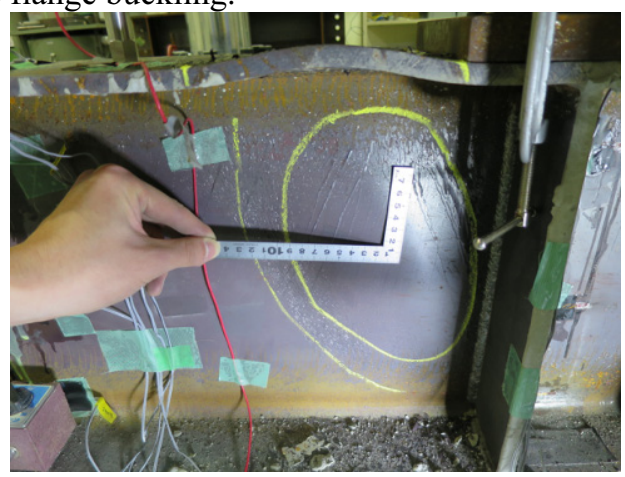

d) The web buckling.

Figure 6. The test failure mode. 
The load-deflection relationship at the middle of the specimen derived from the static failure test is shown in Figure 7. The residual deflection was found to be around $8 \mathrm{~mm}$ due to the fatigue load process. The curve remained elastic until the static load reached to $400 \mathrm{kN}$. The corresponding maximum crack width was found to be $1.2 \mathrm{~mm}$. In fact, the concrete slab was not able to continue supporting the larger load action. Therefore, the structure system transferred from the composite grider to the steel girder for the further load action. Later, the yielding and buckling were found during the flat regime of the curve. The ulitmate deflection of the speicmen was above $40 \mathrm{~mm}$.

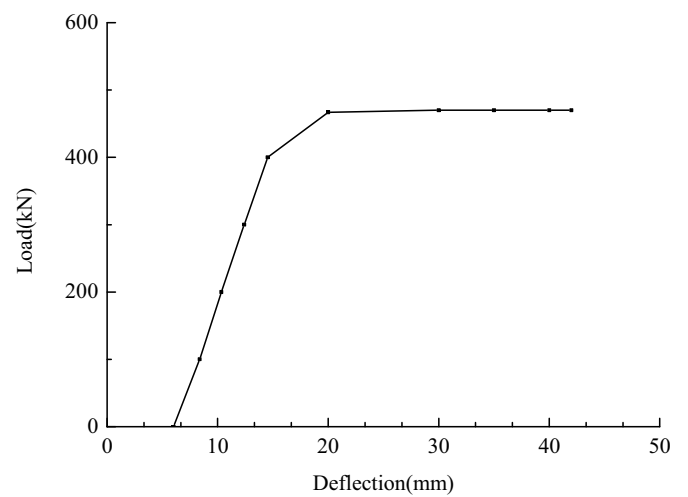

Figure 7. The load-deflection curve in the ulitmate static test.

\subsection{Cyclic test result}

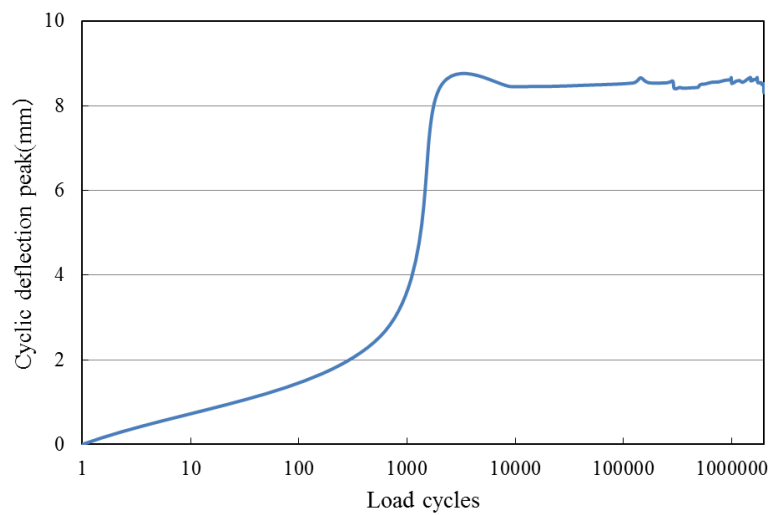

a) Cyclic deflection peak at the middle of the specimen girder.

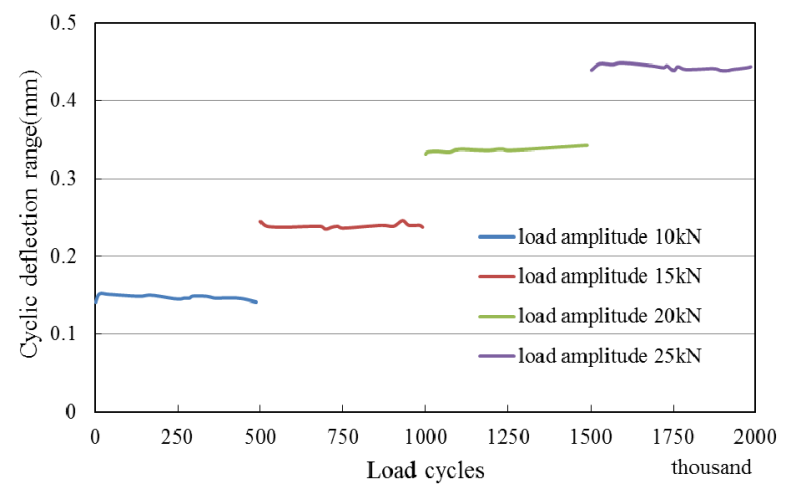

b) Cyclic deflection range at the middle of the specimen girder.

Figure 8. Cyclic deflection feature.
The cyclic deflection feature in the fatigue tests was summarized in Figure 8. Figure 8a shows the cyclic deflection peak at the middle of the specimen girder, corresponding to the cyclic load peak $108 \mathrm{kN}$. The peak value developed fast in the initial load cycles with an amplitude of $80 \mathrm{kN}$. And the development of the peak value turned stable in the other fatigue load procedures. On the other hand, the cyclic deflection range values were presented in Figure $\mathbf{8 b}$ except the values corresponding to the load amplitude of $80 \mathrm{kN}$. All of the values appeared constant in the fatigue load process. The cyclic deflection range of the load cycles with $80 \mathrm{kN}$ amplitude was $0.67 \mathrm{~mm}$.

Meanwhile, the crack development during the fatigue load test was observed carefully. It can be found that the crack distribution area developed gradually with fatigue load cycles. Meanwhile, the maximum crack width development was investigated as well, of which the development feature was in contrast to that of the crack distribution. As shown in Figure 9, the maximum crack width developed with fatigue load cycles until being around $0.42 \mathrm{~mm}$. Since the $0.42 \mathrm{~mm}$, the crack width remained stable to the end of the fatigue test. But on the other hand, the crack amount and distribution area was found to keep developing with fatigue load cycles.

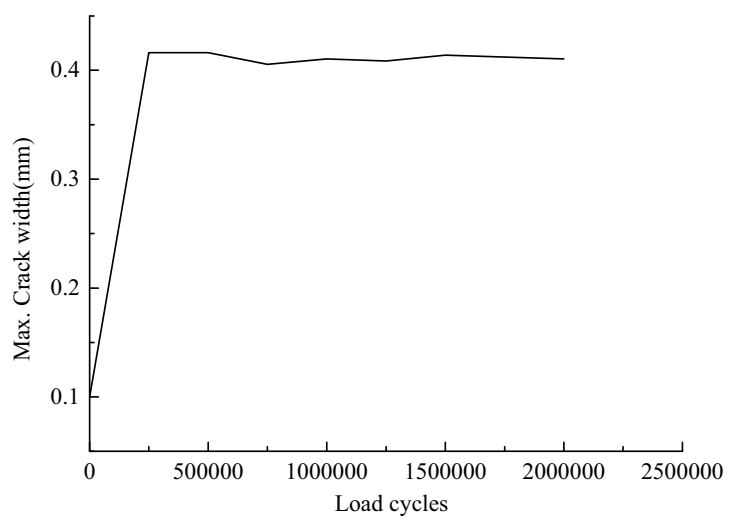

Figure 9. Development of the maximum crack width in the fatigue test.

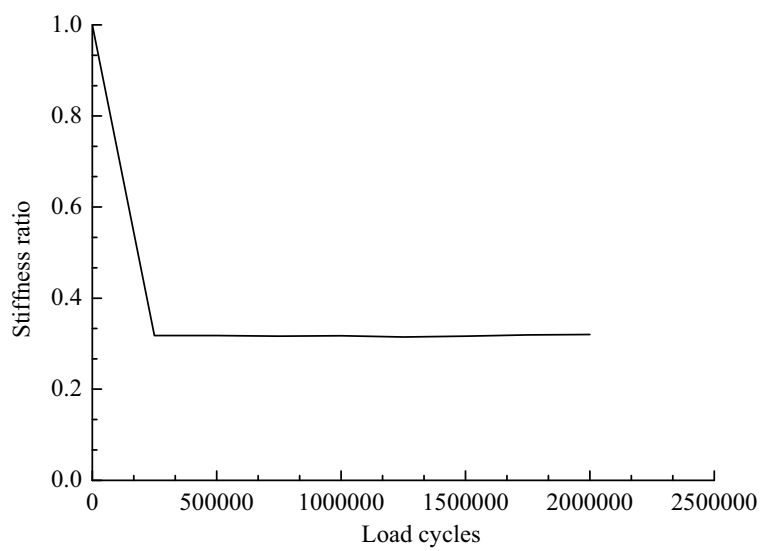

Figure 10. The feature of the stiffness degradation.

Further, the stiffness degradation of the specimen girder due to the fatigue damage was investigated as shown in Figure 10. The stiffness was defined as the ratio of the static load value $(108 \mathrm{kN})$ to the corresponding 
deflection at the middle of the girder specimen. And the stiffness ratio was the ratio of the static stiffness value in fatigue test to the initial stiffness of the intact girder specimen. It can be seen that the stiffness decreased rapidly by $70 \%$ in the initial stage of the fatigue load cycles. But later the stiffness kept being stable to the end of the fatigue test indicating that the global fatigue induced damage was not obvious.

In addition, the steel-SFRC interlayer slips were also observed during the test process as illustrated in Figure 11. The horizontal axis shows the distance of the slip position to the middle of the girder specimen and the vertical axis shows the corresponding slip values. It can be seen the slip direction turned over generally near the center of the specimen. And the maximum slip values can be found near the ends of the specimen. These observations actually confirmed the basic slip feature of the composite girder. Moreover, the slip values at the final situation were obviously larger than the corresponding values of other loading steps. But the slip values except the center of the specimen appeared quite stable during the fatigue load process.

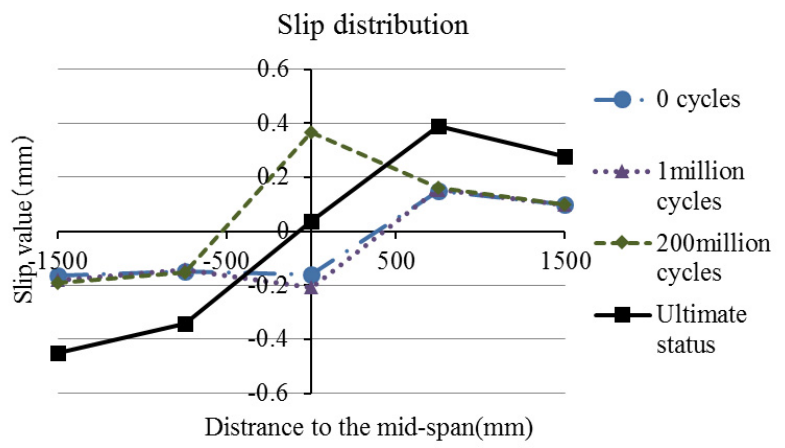

Figure 11. The steel-SFRC interlayer.

Generally, the fatigue induced damage was found to comprise two steps: the initial global mechanical degradation and the local damage development with relatively stable global performance. The local damage in the second step was reflected by the increases of the concrete crack amount and distribution area. Unfortunately, these were not reflected obviously by the global stiffness degradation.

\subsection{Impact test results}

The results of the executed impact tests were summarized in Figure 12 and Figure 13.

Figure 12 shows the frequency spectrums based on the FFT transformations of time domain acceleration data derived from A4(Figure 12a), A5(Figure 12b), A1(Figure 12c), and A8(Figure 12d). They corresponded to the middle parts and the ends of the specimen according to Figure 5. Generally, the vibration features of the four positions appeared identical to each other, indicating the data rationality. In each of the figures, the frequency spectrum curves corresponding to several static and fatigue load situations were compared with each other. The resonance frequency degradation due to the fatigue damage can be summarized in each of the figure. This was different from the stable mechanical performance mainly reflected by deflection stiffness. Furthermore, it can be observed that the additional frequency peaks appeared on the curves during the fatigue damage development compared with the intact frequency spectrum curves. This may be explained by the local damage actually make the structure system different. Moreover, the frequency peak amplitudes were found to be remarkably larger than the ones of the intact curves. In general, the frequency spectrum curves appeared more sensitive than the static stiffness observations to the fatigue-induced damages of the girder specimen.

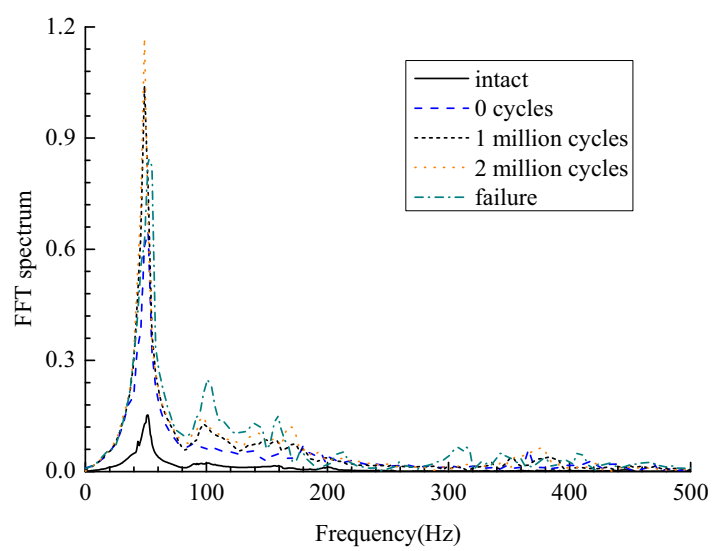

a) The frequency spectrum of A4.

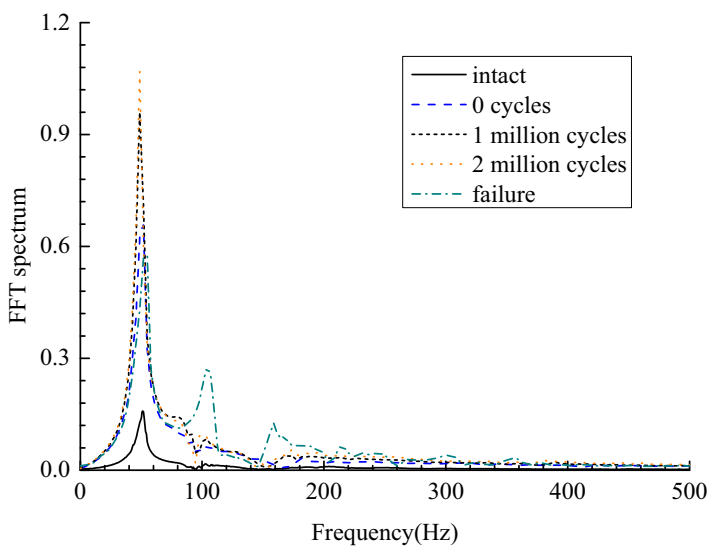

b) The frequency spectrum of A5.

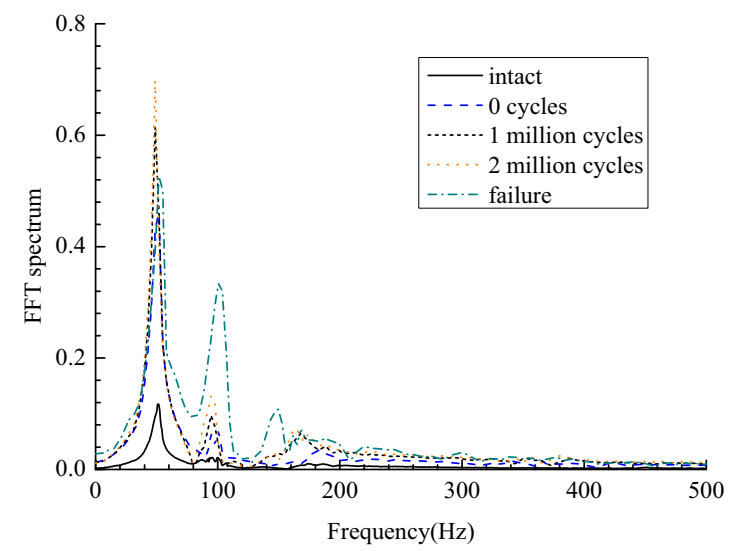

c) The frequency spectrum of A1. 


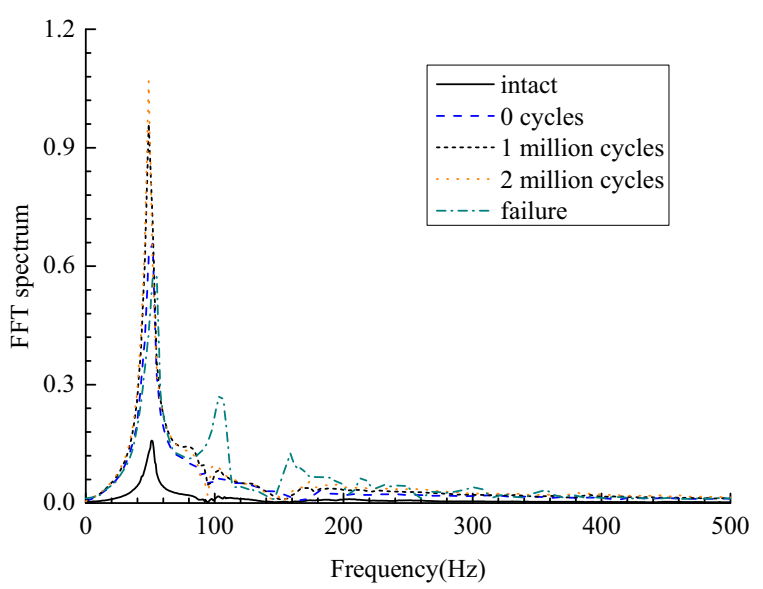

d) The frequency spectrum of A8.

Figure 12. The frequency spectrum.

Figure 13 summarized the normalized vibration modes of the 1st (Figure 13a), 2nd (Figure 13b) and 3rd (Figure 13c) orders. In each of the figures, the frequency spectrum curves corresponding to several static and fatigue load situations were compared with each other. It can be found the mode shapes were not changed significantly by fatigue and even the final static failure. But the normalized mode shape amplitude varied obviously, especially the 2 nd order vibration mode. In this sense, the vibration mode is also more sensitive than the static stiffness degradation observation to the fatigue damage of the girder specimen.

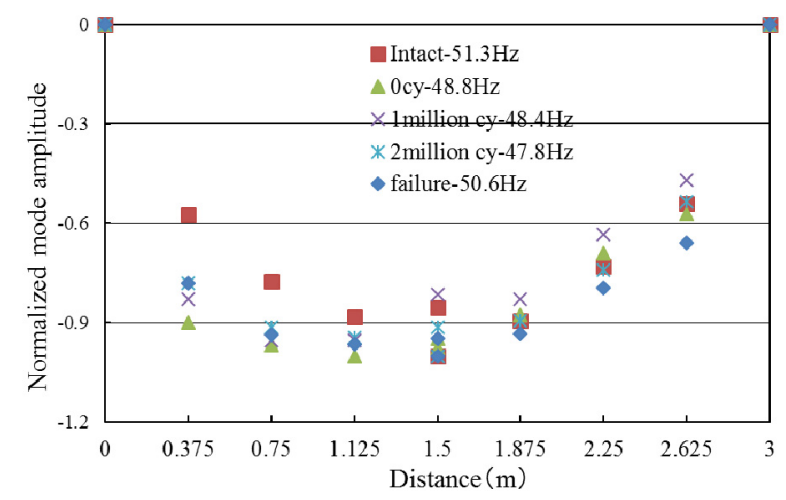

a) The 1 st order vibration modes.

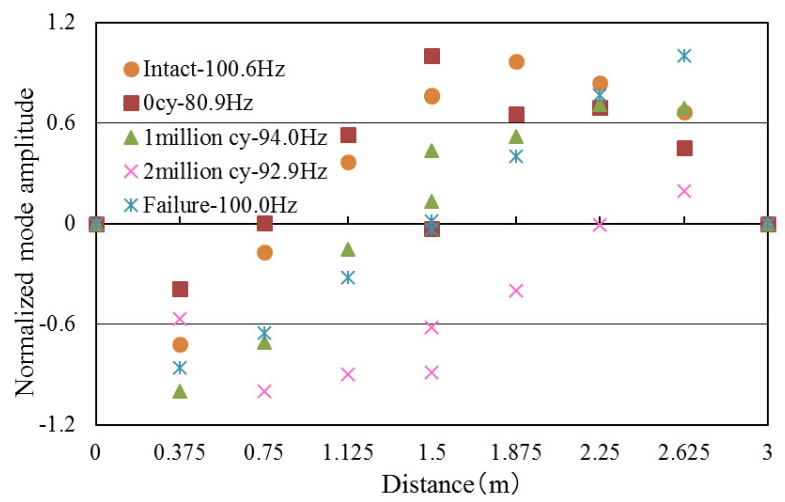

b) The 2nd order vibration modes.

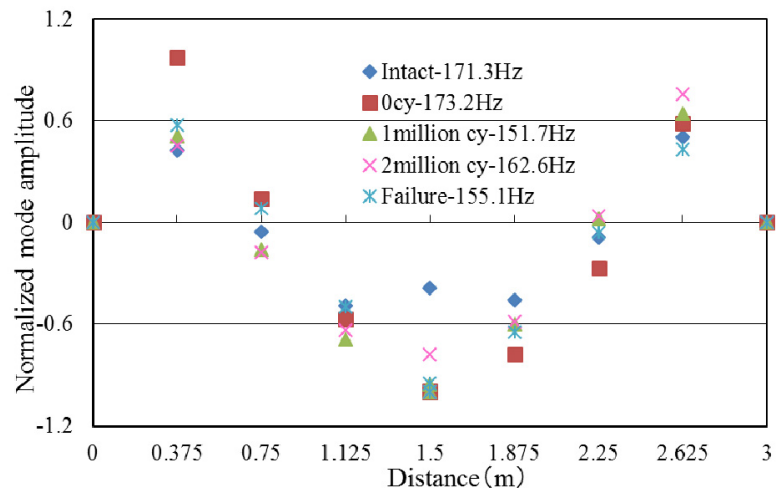

c) The 3rd order vibration modes.

Figure 13. The frequency spectrum.

\section{Conclusion}

The fatigue test on a steel-SFRC composite girder was carried out to investigate the efficiency of vibration based assessment method. The following summations were derived based on the test results.

1. The test failure mode appeared as the concrete slab tensile failure and the following the yielding and buckling at the steel flange and nearby web area. The maximum concrete crack width was $1.9 \mathrm{~mm}$.

2. The fatigue induced damage was found to comprise two steps: the initial global mechanical degradation and the local damage development with relatively stable global performance. The local damage in the second step was reflected by the increases of the concrete crack amount and distribution area. However, these were not reflected obviously by the global stiffness degradation.

3. The frequency spectrum curves derived by impact vibration test appeared more sensitive than the static stiffness observations to the fatigue-induced damages of the girder specimen. Meanwhile, the vibration mode is also more sensitive than the static stiffness degradation observation to the fatigue damage of the girder specimen.

\section{References}

1. Public works research institute. Design and constructional manual of steel bridge deck reinforcement by using SFRC. Research report. Oct., 2009. (In Japanese)

2. Japan Industry Standard. "Method of test for compressive strength of concrete." JIS A 1108: 1998. Japan. [in Japanese]

3. Japan Industry Standard. "Method of test for splitting tensile strength of concrete." JIS A 1113: 1999. Japan. [in Japanese]

4. Japan Industry Standard. "Method of tensile test for metallic materials." JIS Z 2241: 1998. Japan [in Japanese] 